\title{
Impact of base size and shape on formation control of multifaceted InP nanopyramids by selective area metal organic vapor phase epitaxy
}

\section{Citation for published version (APA):}

Yuan, J., Wang, H., Veldhoven, van, P. J., \& Nötzel, R. (2009). Impact of base size and shape on formation control of multifaceted InP nanopyramids by selective area metal organic vapor phase epitaxy. Journal of Applied Physics, 106(12), 124304-1/4. [124304]. https://doi.org/10.1063/1.3267856

DOI:

10.1063/1.3267856

Document status and date:

Published: 01/01/2009

\section{Document Version:}

Publisher's PDF, also known as Version of Record (includes final page, issue and volume numbers)

\section{Please check the document version of this publication:}

- A submitted manuscript is the version of the article upon submission and before peer-review. There can be important differences between the submitted version and the official published version of record. People interested in the research are advised to contact the author for the final version of the publication, or visit the DOI to the publisher's website.

- The final author version and the galley proof are versions of the publication after peer review.

- The final published version features the final layout of the paper including the volume, issue and page numbers.

Link to publication

\footnotetext{
General rights

- You may freely distribute the URL identifying the publication in the public portal. follow below link for the End User Agreement:

www.tue.nl/taverne

\section{Take down policy}

If you believe that this document breaches copyright please contact us at:

openaccess@tue.nl

providing details and we will investigate your claim.
}

Copyright and moral rights for the publications made accessible in the public portal are retained by the authors and/or other copyright owners and it is a condition of accessing publications that users recognise and abide by the legal requirements associated with these rights.

- Users may download and print one copy of any publication from the public portal for the purpose of private study or research.

- You may not further distribute the material or use it for any profit-making activity or commercial gain

If the publication is distributed under the terms of Article 25fa of the Dutch Copyright Act, indicated by the "Taverne" license above, please 


\title{
Impact of base size and shape on formation control of multifaceted InP nanopyramids by selective area metal organic vapor phase epitaxy
}

\author{
Jiayue Yuan, Hao Wang, ${ }^{\text {a) }}$ Peter J. van Veldhoven, and Richard Nötzel \\ COBRA Research Institute, Eindhoven University of Technology, 5600 MB Eindhoven, The Netherlands
}

\begin{abstract}
(Received 29 September 2009; accepted 29 October 2009; published online 17 December 2009)
\end{abstract}

\begin{abstract}
We report the impact of base size and shape on the evolution control of multifaceted InP (100) nanopyramids grown by selective area metal organic vapor phase epitaxy. The pyramid top surfaces are composed of a (100) center facet surrounded by high-index $\{103\}$ and $\{115\}$ facets. Their arrangement and (relative) size depend on the size and shape of the pyramid top area. For a certain shape, only the (100) facet remains below a critical size of the top area. The arrangement and (relative) size of the top facets in turn are governed by the $\{110\}$ and $\{111\}$ side facets whose area (ratio) depends on the pyramid base size and shape. This self-consistently determines the ratio of the (100) top facet area and the sum of the $\{110\}$ and $\{111\}$ side facet areas as well as the height of the pyramids. (C) 2009 American Institute of Physics. [doi:10.1063/1.3267856]
\end{abstract}

\section{INTRODUCTION}

The selective area growth ${ }^{1,2}$ III-V semiconductor nanopyramids have been widely studied in the GaAs based material system by metal organic vapor phase epitaxy (MOVPE), ${ }^{3-6}$ and in the InP based material system by chemical beam epitaxy ${ }^{7}$ and MOVPE. ${ }^{8,9}$ They have been employed as templates for the position controlled growth of InAs quantum dots (QDs), ${ }^{8,10}$ thus enabling a wide range of applications in the field of future quantum functional devices. ${ }^{11-14}$ Here, we study the impact of the size and shape of the base of multifaceted InP nanopyramids on their evolution control during MOVPE. The arrangement and (relative) size of the facets forming the top surface of the pyramids depend on the size and shape of the pyramids top area which, in turn, are governed by the $\{110\}$ and $\{111\}$ side facets whose area (ratio) depends on the pyramids base size and shape. This directly determines the ratio of the (100) top facet area and the sum of the $\{110\}$ and $\{111\}$ side facet areas as well as the height of the pyramids. Our study is the basis for the position and distribution control of InAs QDs required for efficient QD nanolasers and single photon sources emitting around $1.55 \mu \mathrm{m}$ in combination with submicrometer-scale active-passive integration ${ }^{9}$ for their implementation in photonic integrated circuits.

\section{EXPERIMENTAL PROCEDURE}

A $100 \mathrm{~nm}$ thick $\mathrm{SiN}_{x}$ mask layer was deposited on the semi-insulating InP (100) substrates, $2^{\circ}$ misorientated toward (110), by plasma-enhanced chemical-vapor deposition. The openings in the $\mathrm{SiN}_{x}$ layer were created by electron beam lithography and reactive ion etching. The openings were arranged in a square lattice with center-to-center distance of $10 \mu \mathrm{m}$. Three characteristic shapes were fabricated: square with side length along [001] (square-[001]), square with side length along [01-1] (square-[01-1]), and circular. The side

\footnotetext{
a) Author to whom correspondence should be addressed. Electronic mail: h.wang@tue.nl.
}

lengths or diameters of the openings were varied between $500 \mathrm{~nm}$ and $1.5 \mu \mathrm{m}$. Selective area growth was carried out by low-pressure MOVPE using trimethyl-indium and tertiarybutyl-phosphine, diluted in $\mathrm{H}_{2}$, as source materials. The growth temperature was $610{ }^{\circ} \mathrm{C}$, the growth rate was $18.39 \mathrm{~nm} / \mathrm{min}$ in unmasked areas, and the reactor pressure was reduced to 75 Torr to enhance the In adatom surface migration length for well-defined pyramid formation. The total growth time was $4.13 \mathrm{~min}$. The morphology of the InP pyramids was characterized by tapping mode atomic force microscopy (AFM) in air.

\section{RESULTS AND DISCUSSION}

Figure 1 shows the AFM images together with schematic drawings of the different truncated InP pyramids for various size and shape of the mask openings, i.e., pyramids base: (a), (b) squares with side along [001], (c), (d) squares with side along [01-1], and (e), (f) circulars. The top surface of the large pyramids is composed of a (100) central facet and highindex $\{103\}$ and $\{115\}$ facets around. The small pyramids only exhibit a (100) top facet. The pyramids side walls are bound by $\{110\}$ and $\{111\}$ side facets. The facets are identified from their inclinations with respect to the substrate surface determined by AFM line scans. ${ }^{15}$ In detail, square[01-1] and circular based pyramids are bound by four $\{110\}$ and four $\{111\}$ side facets with, however, different area ratio determined by the pyramids base size and shape. Square[001] based pyramids are bound by four $\{110\}$ side facets. As the $\{103\}$ and $\{115\}$ top facets are connected to the $\{110\}$ and $\{111\}$ side facets, respectively, and surround the (100) central facet, the arrangement and (relative) size of the pyramids top facets depend on the size and shape of the pyramids top area and base. This is summarized in Fig. 2 where the ratio of the (100) facet area and the total top surface area is plotted as a function of the top surface area for various shapes. The ratio is largest for square-[001] pyramids and smallest for square [01-1] pyramids. This indicates that the ratio is governed by the appearance of $\{115\}$ facets, being largest when they are suppressed. The ratio sharply increases for top areas between 

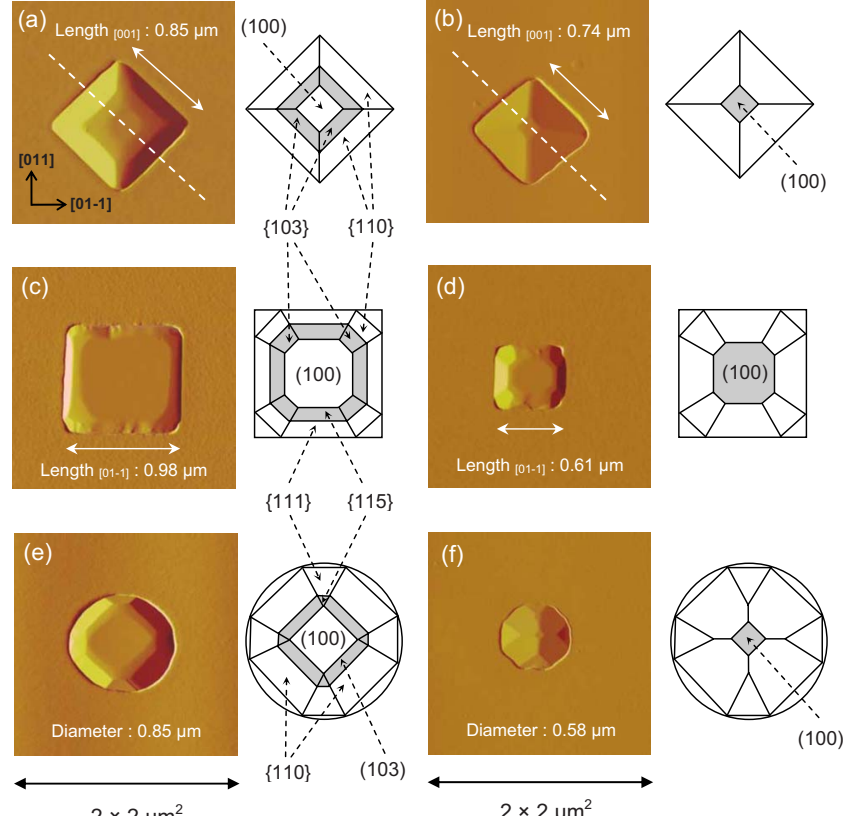

(100)

$2 \times 2 \mu m^{2}$

$2 \times 2 \mu \mathrm{m}^{2}$

FIG. 1. (Color online) AFM images of the truncated InP pyramids together with schematic drawings for various base shapes: (a), (b) squares with side along [001], (c), (d) squares with side along [01-1], and (e), (f) circulars. The dashed white lines in (a), (b) indicate the directions of the line scans shown in Fig. 3. The scan fields are $2 \times 2 \mu \mathrm{m}^{2}$.

0.3 and $0.7 \mu \mathrm{m}^{2}$, indicated by the arrow in Fig. 2. This indicates the suppression of the high-index facets below a certain size of the pyramid top area. This is evaluated by the AFM line profiles, shown in Figs. 3(a) and 3(b), along [001] across the square-[001] based pyramids as indicated in Figs. 1(a) and 1(b) by the dashed white lines.

The large pyramid exhibits an extended $\{103\}$ facet between the $\{110\}$ and $\{100\}$ facets with angles between the facets of 153 and $165^{\circ}$, respectively. For the small pyramid, the $\{110\}$ and $(100)$ facets are directly connected with an angle between the facets of $136^{\circ}$. The suppression of the high-index facets with reduced top area is understood by a competition between surface energy and edge energy to

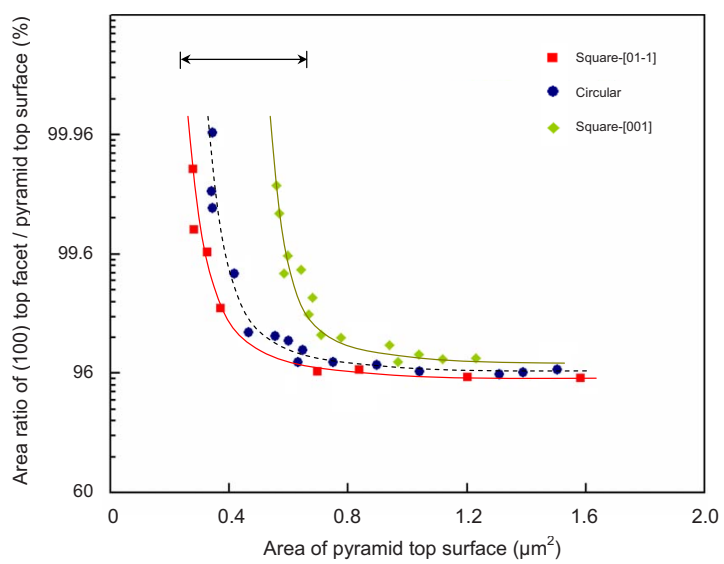

FIG. 2. (Color online) Ratio of (100) top facet area divided by the total pyramid top surface area as a function of the top surface area for various base shapes: Square with side along [001] (square-[001]), square with side along [01-1] (square-[01-1]), and circular. The dashed and solid lines indicate the general trends. The black arrow indicates the area of pyramid top surface between $0.3-0.7 \mu \mathrm{m}^{2}$.
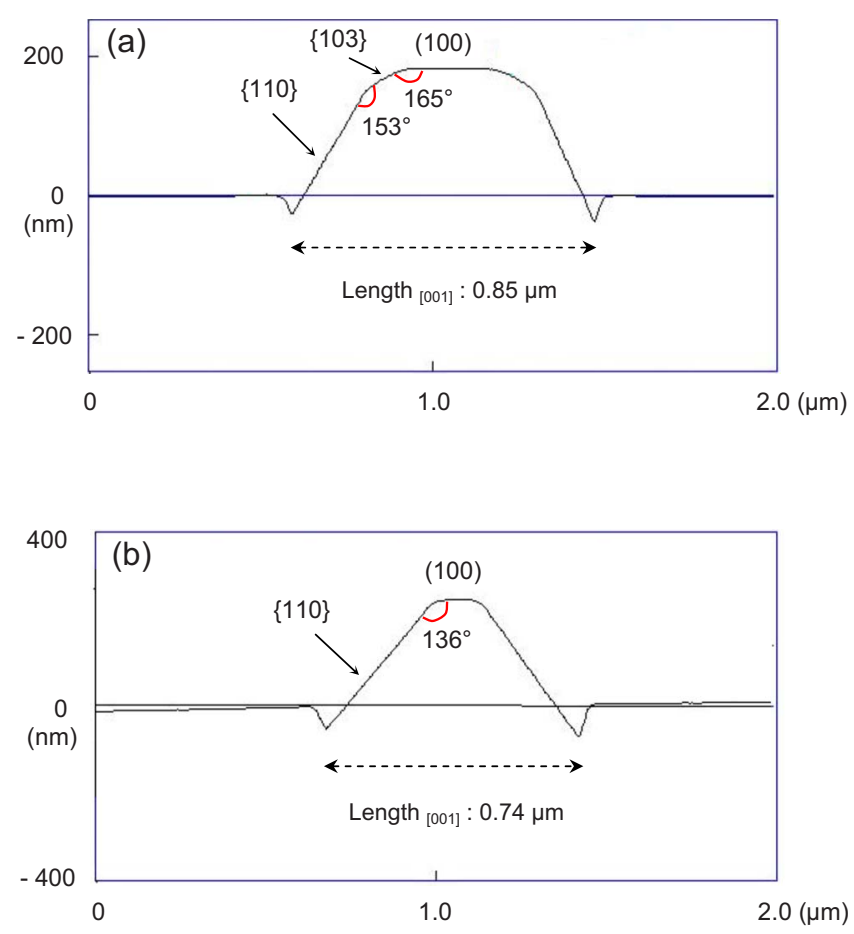

FIG. 3. (Color online) Cross-sectional AFM line profiles of square-based pyramids with side along [001] taken along [001] with (a) 0.85 and (b) $0.74 \mu \mathrm{m}$ side length.

minimize the total surface energy. ${ }^{16,17}$ Even if the surface energy of the high-index facets is larger than that of the (100) top facet, the introduction of two edges with larger angles in the presence of high-index facets, lowers the total surface energy compared to the case of direct connection of the (100) top facet with the $\{110\}$ side facets, resulting in a sharper edge with smaller angle, contributing a larger edge energy. Below a certain size of the high-index facets for reduced top area, however, the two edges approach each other and the formation of a single edge becomes beneficial, resulting in the disappearance of the high-index facets.

The evolution of the pyramids sidewalls is governed by the competition between the $\{111\}$ and $\{110\}$ facets for a given base shape. In Fig. 4, their area ratio for various base shapes is plotted as a function of the area of the pyramids

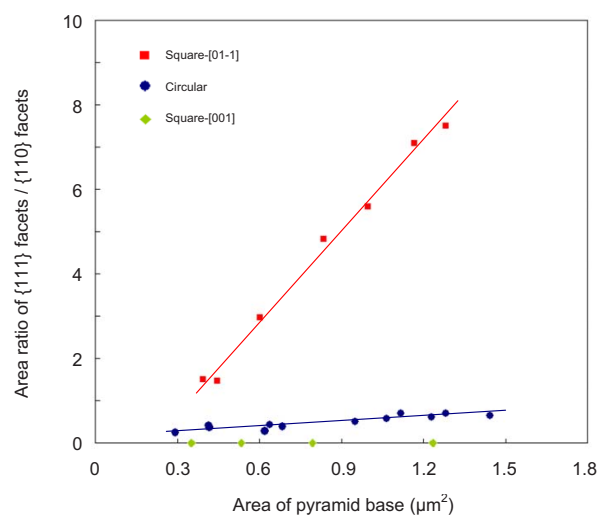

FIG. 4. (Color online) Ratio of the $\{111\}$ and $\{110\}$ side facet areas vs area of the pyramid base for various base shapes: square with side along [001] (square-[001]), square with side along [01-1] (square-[01-1]), and circular. The solid lines indicate the general trends. 


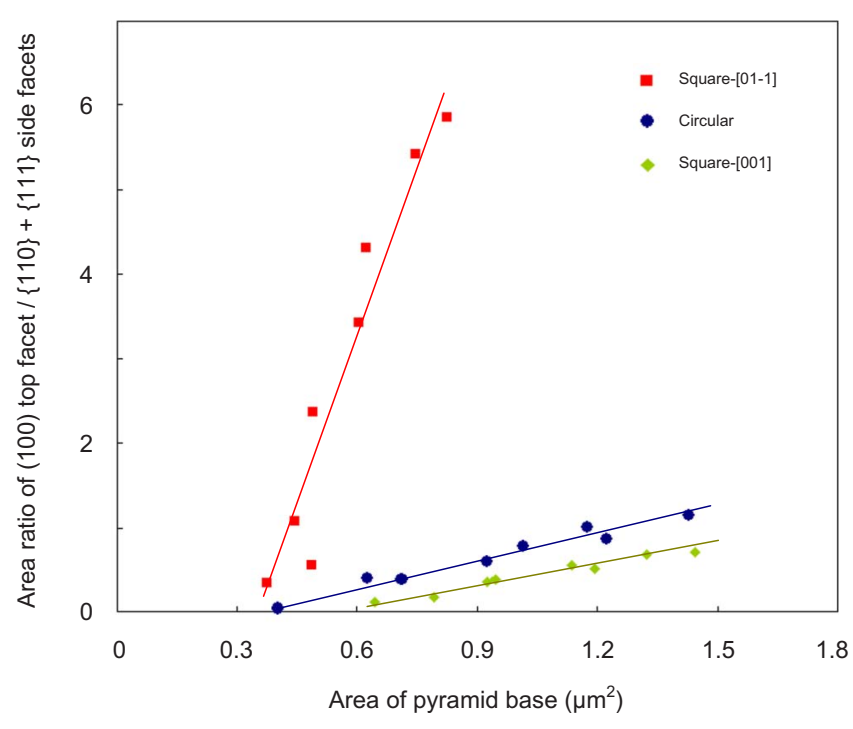

FIG. 5. (Color online) Ratio of the (100) facet area and the sum of the $\{110\}$ and $\{111\}$ facet areas vs area of the pyramid base for various base shapes: Square with side along [001] (square-[001]), square with side along [01-1] (square-[01-1]), and circular. The solid lines indicate the general trends.

base. There is a clear trend that the relative area of the $\{111\}$ facets decreases compared to that of the $\{110\}$ facets with reduction of the base size. This decrease is stronger, the larger the area ratio is, given by the base shape. The ratio of the areas of the $\{111\}$ and $\{110\}$ facets is directly related to the ratio of the areas of the $\{115\}$ and $\{103\}$ facets on the pyramids top and therefore consistent with Fig. 2 showing the ratio of the area of the (100) top facet and the total top area being larger for smaller relative area of the $\{115\}$ facets.

The relative area of the $\{111\}$ and $\{110\}$ side facets is also directly related to the ratio of the (100) top facet area and the total sidewall area shown in Fig. 5, as well as the pyramids height as function of the area of the pyramids base, shown in Fig. 6. The angle between the $\{111\}$ facets and the (100) surface is $54.7^{\circ}$ and that between the $\{110\}$ facets and the (100) surface is $45^{\circ} .{ }^{18}$ Hence, the larger the fraction of the $\{111\}$ facets is, given by the base shape, the steeper, on

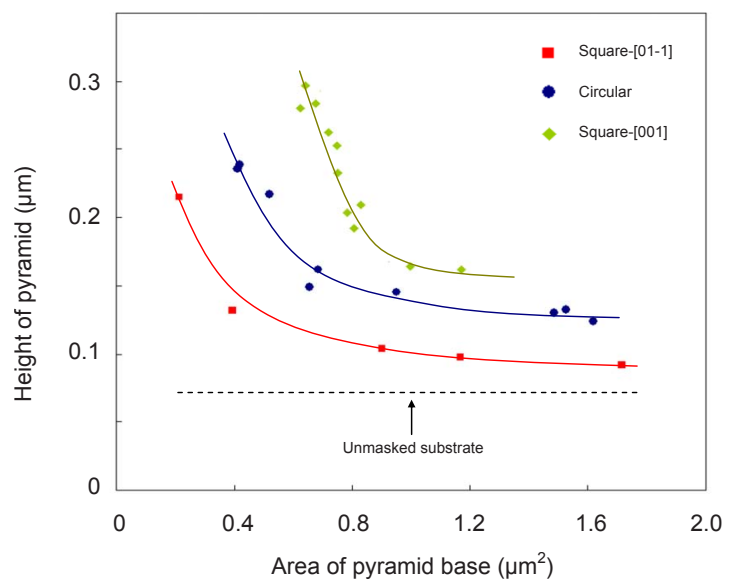

FIG. 6. (Color online) Height of the truncated pyramids vs area of the base for various base shapes: Square with side along [001] (square-[001]), square with side along [01-1] (square-[01-1]), and circular. The solid lines indicate the general trends and the dashed line represents the layer thickness on unmasked substrates. average, are the pyramids sidewalls. Therefore, the relative area of the (100) top facet is larger (of course the area of the (100) top facet and therefore the area ratio plotted in Fig. 5 reduces for all shapes with reducing base area), and the height is smaller due to the smaller relative growth rate enhancement (of course the height plotted in Fig. 6 increases for all shapes with reducing base area due to the increasing growth rate enhancement).

The results plotted in Figs. 4 and 5 can be related to the total surface energy, when neglecting the contribution of the high-index facets due to their relatively small areas. The surface energies of the (111) and (-1-1-1) facets are 6.2 and $4.4 \mathrm{eV} / \mathrm{nm}^{2}$, respectively, and the surface energy of the (110) facet is $5.5 \mathrm{eV} / \mathrm{nm}^{2} .{ }^{17}$ For the symmetric pyramids this would favor the formation of $\{111\}$ side facets rather than $\{110\}$ side facets. However, in this case the relative area of the (100) top facet, having the largest surface energy of $6.2 \mathrm{eV} / \mathrm{nm}^{2}$, is larger. Therefore, $\{110\}$ rather than $\{111\}$ side facets preferably form, most pronounced for small pyramids which are close to pinch-off, to minimize the total surface energy.

\section{CONCLUSIONS}

In summary, we have reported the impact of base size and shape to control the evolution of multifaceted InP nanopyramids grown by selective area MOVPE. Large base sizes lead to truncated pyramids with the top surfaces composed of a (100) center facet and naturally formed $\{103\}$ and $\{115\}$ facets around. In contrast, small base sizes lead to formation of only a (100) top facet. The arrangement and (relative) size of the facets are governed by the size and shape of the pyramids top area. The arrangement and (relative) size of the top facets in turn are governed by the $\{110\}$ and $\{111\}$ side facets whose area (ratio) depends on the pyramids base size and shape. This directly determines the ratio of the (100) top facet area and the sum of the $\{110\}$ and $\{111\}$ side facet areas, related to the minimization of the total surface energy, as well as the height of the pyramids. These findings are the basis to control the distribution (on the high-index facets for large top area) and number (on the (100) top facets for small top area) of InAs QDs deposited on these InP nanopyramids. ${ }^{8}$

\section{ACKNOWLEDGMENTS}

The authors gratefully acknowledge the support of the Smart Mix Programme of the Netherlands Ministry of Economic Affairs and the Netherlands Ministry of Education, Culture and Science.

${ }^{1}$ J. Takeda, M. Akabori, J. Motohisa, R. Nötzel, and T. Fukui, Nanotechnology 16, 2954 (2005).

${ }^{2}$ T. Ujihara, Y. Yoshida, W. S. Lee, and Y. Takeda, J. Cryst. Growth 289, 89 (2006).

${ }^{3}$ G. J. Bauhuis, P. Mulder, and H. van Kempen, J. Cryst. Growth 240, 104 (2002).

${ }^{4}$ B. L. Liang, P. S. Wong, N. Nuntawong, A. R. Albrecht, J. Tatebayashi, T. J. Rotter, G. Balakrishnan, and D. L. Huffakerb, Appl. Phys. Lett. 91, 243106 (2007)

${ }^{5}$ P. S. Wong, G. Balakrishnan, N. Nuntawong, J. Tatebayashi, and D. L. Huffaker, Appl. Phys. Lett. 90, 183103 (2007). 
${ }^{6}$ H. S. Chang, C. M. Hsu, W. Y. Chen, T. P. Hsieh, J. I. Chyi, and T. M. Hsu, Nanotechnology 19, 045714 (2008).

${ }^{7}$ D. Chithrani, R. L. Williams, J. Lefebvre, P. J. Poole, and G. C. Aers, Appl. Phys. Lett. 84, 978 (2004).

${ }^{8}$ H. Wang, J. Yuan, T. Rieger, P. J. van Veldhoven, P. Nouwens, T. J. Eijkemans, T. de Vries, E. Smalbrugge, E. J. Geluk, and R. Nötzel, Appl Phys. Lett. 94, 143103 (2009).

${ }^{9}$ D. Zhou, S. Anantathanasarn, P. J. van Veldhoven, F. W. M. van Otten, T. J. Eijkemans, T. de Vries, E. Smalbrugge, and R. Nötzel, Appl. Phys. Lett. 91, 131102 (2007).

${ }^{10}$ T. Tran, A. Muller, C. K. Shih, P. S. Wong, G. Balakrishnan, N. Nuntawong, J. Tatebayashi, and D. L. Huffaker, Appl. Phys. Lett. 91, 133104 (2007).

${ }^{11}$ P. Michler, A. Kiraz, C. Becher, W. V. Schoenfeld, P. M. Petroff, L. Zhang,
E. Hu, and A. Imamoglu, Science 290, 2282 (2000).

${ }^{12}$ C. Santori, M. Pelton, G. Solomon, Y. Dale, and Y. Yamamoto, Phys. Rev. Lett. 86, 1502 (2001).

${ }^{13}$ S. Laurent, S. Varoutsis, L. Le Gratiet, A. Lemaître, I. Sagnes, F. Raineri, A. Levenson, I. Robert-Philip, and I. Abram, Appl. Phys. Lett. 87, 163107 (2005).

${ }^{14}$ T.-P. Hsieh, J.-I. Chyi, H.-S. Chang, W.-Y. Chen, T. M. Hsu, and W.-H. Chang, Appl. Phys. Lett. 90, 073105 (2007).

${ }^{15}$ H. Wang, G. Zeng, Z. Song, Y. Wu, C. Liao, X. Le, J. Cai, and S. Liu, J. Cryst. Growth 279, 241 (2005).

${ }^{16}$ N. Moll, M. Scheffler, and E. Pehlke, Phys. Rev. B 58, 4566 (1998).

${ }^{17}$ Q. K. K. Liu, N. Moll, M. Scheffler, and E. Pehlke, Phys. Rev. B 60, 17008 (1999).

${ }^{18}$ R. M. Bozorth, Phys. Rev. 26, 390 (1925). 